\title{
Weight loss-induced stress in subcutaneous adipose tissue is related to weight regain
}

\author{
Nadia J. T. Roumans*, Stefan G. Camps, Johan Renes, Freek G. Bouwman, Klaas R. Westerterp and \\ Edwin C. M. Mariman \\ Department of Human Biology, Maastricht University, 6200 MD Maastricht, The Netherlands
}

(Submitted 9 July 2015 - Final revision received 12 November 2015 - Accepted 26 November 2015 - First published online 13 January 2016)

\section{Abstract}

Initial successful weight loss is often followed by weight regain after the dietary intervention. Compared with lean people, cellular stress in adipose tissue is increased in obese subjects. However, the relation between cellular stress and the risk for weight regain after weight loss is unclear. Therefore, we determined the expression levels of stress proteins during weight loss and weight maintenance in relation to weight regain. In vivo findings were compared with results from in vitro cultured human Simpson-Golabi-Behmel syndrome (SGBS) adipocytes. In total, eighteen healthy subjects underwent an 8-week diet programme with a 10-month follow-up. Participants were categorised as weight maintainers or weight regainers (WR) depending on their weight changes during the intervention. Abdominal subcutaneous adipose tissue biopsies were obtained before and after the diet and after the follow-up. In vitro differentiated SGBS adipocytes were starved for $96 \mathrm{~h}$ with low $(0.55 \mathrm{~mm})$ glucose. Levels of stress proteins were determined by Western blotting. WR showed increased expressions of $\beta$-actin, calnexin, heat shock protein (HSP) 27, HSP60 and HSP70. Changes of $\beta$-actin, HSP27 and HSP70 are linked to HSP60, a proposed key factor in weight regain after weight loss. SGBS adipocytes showed increased levels of $\beta$-actin and HSP60 after $96 \mathrm{~h}$ of glucose restriction. The increased level of cellular stress proteins in the adipose tissue of WR probably resides in the adipocytes as shown by in vitro experiments. Cellular stress accumulated in adipose tissue during weight loss may be a risk factor for weight regain.

\section{Key words: Weight loss: Weight regain: Adipocytes: Cellular stress: Stress proteins}

The prevalence of overweight and obesity has risen in recent years, causing a worldwide public health problem due to an increased risk for the metabolic syndrome and development of type 2 diabetes, CVD and cancer. This risk can be significantly lowered by losing weight ${ }^{(1)}$. Usually, losing weight can be readily achieved, but sustaining the lower weight is problematic. Successfully maintaining weight loss, defined as 'keeping off an intentional loss of at least $10 \%$ body weight for at least one year $^{\text {(2) }}$, is proven to be difficult. In general, up to $80 \%$ of the people are unsuccessful ${ }^{(3,4)}$ and their risk for metabolic complications after weight regain appears even higher than that at the start of the weight-loss period ${ }^{(5,6)}$. It is therefore of great importance to understand the mechanisms that influence the risk for weight regain. Many studies have already shown the involvement of various psychosocial and lifestyle factors in weight maintenance such as motivation to lose weight, social support, physical activity and eating habits ${ }^{(3,7)}$. Other studies have shown effects of physiological and molecular parameters on weight maintenance - for example, increased insulin sensitivity after weight loss is associated with weight regain ${ }^{(8,9)}$. In addition, fasting insulin and homeostasis model assessment of insulin resistance (HOMA-IR) are associated with weight regain ${ }^{(10)}$.
Wang et al. ${ }^{(11)}$ showed that men with the metabolic syndrome at baseline were more at risk for weight regain than men without this condition. Further, it has been shown that a higher protein intake after weight loss improves weight maintenance ${ }^{(12)}$. Irisin levels decrease when body weight is reduced but returns to baseline levels in subjects regaining the lost weight ${ }^{(13)}$. All these findings indicate the involvement of various factors in weight regain or maintenance after weight loss. Studies have pointed at special roles of sex hormones ${ }^{(11)}$, metabolic factors ${ }^{(11,14)}$, hunger and satiety hormones ${ }^{(15)}$ as well as epigenetic modifications such as methylation of the neuropeptide $\mathrm{Y}$ and pro-opiomelanocortin gene promoters in maintenance of weight loss ${ }^{(16)}$. The present study focused particularly on the adipose tissue as a key player for weight regain or maintenance after weight loss.

Baseline BMI, fat mass and plasma leptin concentrations are associated with increased risk for weight regain, indicating an important role for adipocytes ${ }^{(17,18)}$. Mauriège et al. ${ }^{(19)}$ showed that metabolic parameters of the subcutaneous adipose tissue are related to weight regain. Change of lipoprotein lipase activity during weight loss was negatively related to weight regain in women, whereas change of alpha 2 adrenergic receptor ( $\alpha 2-\mathrm{AR})$ was positively related to weight regain in men. The latter effect

Abbreviations: BiP, binding Ig protein; ER, endoplasmic reticulum; HSP, heat shock protein; SGBS, Simpson-Golabi-Behmel Syndrome; SOD, superoxide dismutase; WM, weight maintainers; WR, weight regainers.

* Corresponding author: N. J. T. Roumans, fax +31 43 3670976, email n.roumans@maastichtuniversity.nl 
seems to occur despite the fact that adrenaline-stimulated lipolysis returns to pre-diet levels during the weight-maintenance phase ${ }^{(20)}$. In a weight loss-maintenance study, Verhoef et al. ${ }^{(21)}$ observed that the change in weight during follow-up was related to a change in the levels of the lipolytic enzyme adipose triglyceride lipase in adipose tissue during weight loss. Compared with lean people, the subcutaneous adipose tissue of obese people shows higher endoplasmic reticulum (ER) stress at the level of proteins and gene expression ${ }^{(22)}$. Sharma et al. $^{(23)}$ reported a positive correlation between BMI and activating transcription factor 67 (ATF67)-induced ER stress markers. Human individuals losing weight after a gastric bypass showed decreased levels of ER stress in the adipose tissue, linking weight changes directly to ER stress ${ }^{(24)}$. Although those findings suggest that cellular stress is a consequence of weight gain, it might well be that cellular stress is also a factor that stimulates accumulation of fat. In fact, reactive oxygen species promote the initiation of adipogenesis as well as the terminal differentiation of adipocytes ${ }^{(25,26)}$. In this regard, we hypothesised that cellular stress of adipocytes could also play a role in the risk for weight regain after weight loss. In order to investigate this, we have compared levels of stress-related proteins in the adipose tissue from overweight men and women during weight loss and follow-up. In addition, we compared in vivo findings with observations from in vitro cultured adipocytes after glucose restriction. As stress markers, we selected eight different proteins, which are all involved in different aspects of cellular stress; these were $\beta$-actin, binding Ig protein (BiP), calnexin, heat shock protein (HSP) 27, HSP60, HSP70, superoxide dismutase (SOD) 1 and SOD2. $\beta$-Actin is a component of actin microfilaments that provide structural support and mediate cellular motion $^{(27)}$. BiP is involved in translocation, folding and assembly of secretory and transmembrane proteins within the $\mathrm{ER}^{(28)}$. Calnexin is a Ca-binding protein involved in proper folding of glycoproteins in the $\mathrm{ER}^{(29,30)}$. HSP27 activates the proteasome to degrade unnecessary or damaged proteins ${ }^{(31,32)}$, whereas HSP60 acts as a chaperonin for proteins to be transported to the mitochondrion $^{(22)}$. HSP60 is also released because of inflammatory stress to exert autocrine/paracrine effects on adipocytes ${ }^{(33)}$. HSP70 binds to misfolded proteins after stress-induced protein damage $^{(34)}$. SOD 1 and 2 catalyse conversion of superoxide radicals into peroxide and $\mathrm{O}_{2}$ to defend the cell against oxidative stress $^{(35)}$. These specific proteins have been selected because several studies have already shown that they can be regarded as markers of cellular stress, such as ER stress and oxidative stress $^{(27-30,33,35)}$. Furthermore, based on proteomics observations, Wang et al. $^{(36)}$ have suggested an association between these proteins and cellular stress.

Our objective was to test the hypothesis that altered expressions of the above-mentioned proteins during weight loss and follow-up are related to the risk for weight regain.

\section{Methods}

\section{Subjects and study design}

The eighteen subjects of the present study (nine females, nine males), aged 20-55 years with a BMI of $27-39 \mathrm{~kg} / \mathrm{m}^{2}$, were selected from a larger cohort, who underwent a weight loss-maintenance intervention ${ }^{(21)}$. This study was conducted according to the Declaration of Helsinki guidelines and is registered on ClinicalTrials.gov (registration number: NCT01015508). All procedures involving human participants were approved by the Central Committee on Human Research and by the Medical Ethical Committee of Maastricht University, The Netherlands. Written informed consent was obtained from all the subjects.

Selection of the eighteen subjects was based on their weight change throughout the intervention. In short, subjects were healthy, non-smokers and were not using medications (except for women using oral contraceptives). All subjects maintained a stable weight for three months before the intervention. Participants followed an 8-week, very low-energy diet with about $2 \cdot 1 \mathrm{MJ} / \mathrm{d}$ (Modifast; Nutrition et Santé Benelux). The diet provided $50 \mathrm{~g}$ carbohydrates, $52 \mathrm{~g}$ proteins, $7 \mathrm{~g}$ fat and a micronutrient content, which met the Dutch recommended daily intake. Following weight loss, subjects were instructed to maintain their new body weight for a period of 10 months without following a prescribed diet. However, subjects did receive advice on monitoring and limiting food intake. At three time points - before diet ( $\mathrm{t} 0$ ), after diet ( $\mathrm{t} 2$ ) and after a 10-month follow-up (t12) - adipose tissue biopsies and plasma samples were obtained. Body weight was measured in underwear after overnight fasting using a calibrated scale of the BodPod ${ }^{\circledR}$.

Test subjects were classified into two groups according to the percentage weight loss during the diet and percentage weight regain during follow-up: weight maintainers (WM) and weight regainers (WR). Participants were categorised as WM if there was a weight reduction of at least $10 \%$ but then regained $<6 \%$ weight during follow-up. Participants were categorised as WR if there was a weight reduction of at least $10 \%$ but then regained $6 \%$ or more weight.

\section{Adipose tissue biopsies and protein isolation}

Abdominal subcutaneous adipose tissue biopsies were obtained by needle biopsy under local anaesthesia ( $2 \%$ lidocaine; Fresenius Kabi) after an overnight fast. Tissue samples were immediately rinsed in saline, frozen in liquid $\mathrm{N}_{2}$ and stored at $-80^{\circ} \mathrm{C}$ until protein isolation.

About $350 \mathrm{mg}$ of frozen adipose tissue was ground in a mortar with liquid $\mathrm{N}_{2}$. The powder was dissolved in $200 \mu \mathrm{l}$ of 8 M-urea, $2 \%(\mathrm{w} / \mathrm{v})$ 3-[(3-cholamidopropyl)dimethylammonio]-1propanesulfonate (CHAPS) and $65 \mathrm{~mm}$-dithiothreitol/100 $\mathrm{mg}$ biopsy and vortexed for $5 \mathrm{~min}$. The homogenate was centrifuged for $30 \mathrm{~min}$ at $14000 \mathrm{rpm}$ at $10^{\circ} \mathrm{C}$. The supernatant was carefully collected, aliquoted and stored at $-80^{\circ} \mathrm{C}$ until Western blotting. Protein concentrations were determined by a Bradfordbased protein assay (Bio-Rad).

\section{In vitro cell culture experiments}

Human Simpson-Golabi-Behmel syndrome (SGBS) cells were cultured and differentiated as described previously ${ }^{(37)}$. In brief, SGBS pre-adipocytes were cultured in a T25 flask till $90 \%$ confluence was achieved in Dulbecco's modified Eagle's medium: Nutrient Mixture F-12 (DMEM/F12) medium supplemented with $1 \%$ penicillin/streptomycin (Life Technologies), $10 \%$ fetal 
bovine serum (Bodinco), 66 nm-biotin and 33 nm-D-pantothenic acid (Sigma-Aldrich). Confluent pre-adipocytes were split into two 150-mm petri dishes: a starvation dish and a control dish. In parallel, the two dishes were cultured until 80-90\% confluence was achieved in the same medium as described above. The medium was changed every 2-3d. To induce differentiation, confluent pre-adipocytes were washed with PBS buffer and the medium was changed to serum-free DMEM/F12 medium containing $\quad 0.5 \mathrm{~mm}$-3-isobutyl-1-methylxanthine (IBMX), $25 \mathrm{~nm}$ dexamethasone, $2 \mu \mathrm{m}$-rosiglitazone, $0.01 \mathrm{mg} / \mathrm{ml}$ human transferrin, $20 \mathrm{~nm}$-insulin, $100 \mathrm{~nm}$-cortisol and $0 \cdot 2 \mathrm{~nm}$-triiodothyronine (Sigma-Aldrich). After $4 \mathrm{~d}$, cells were further cultured in serum-free DMEM/F12 medium containing 20 nm-insulin, 100 nM-cortisol, $0.01 \mathrm{mg} / \mathrm{ml}$ human transferrin and 0.2 nm-triiodothyronine. Every 2 d, the medium was refreshed. After $14 \mathrm{~d}, 65-80 \%$ of the pre-adipocytes differentiated into mature adipocytes.

For starvation experiments, mature adipocytes were cultured in DMEM/F12 medium without glucose and supplemented with $1 \%$ penicillin/streptomycin, $20 \mathrm{~nm}$-insulin and $0.55 \mathrm{~mm}$-glucose for a period of $96 \mathrm{~h}$ as glucose restriction to lose fat ${ }^{(38)}$. As control, mature adipocytes, originating from the same pre-adipocyte as the starved adipocytes, were cultured in the same medium with 17.5 mm-glucose. After $96 \mathrm{~h}$, cells were lysed using radioimmunoprecipitation assay buffer, and protein concentrations were determined using the Pierce BCA Protein Assay Kit (Thermo Fisher). Samples were stored at $-80^{\circ} \mathrm{C}$ until Western blotting. This entire procedure was performed three times in parallel to create three separate experiments.

\section{Western blotting}

A total of $15 \mu \mathrm{g}$ of protein from in vitro or in vivo samples was separated on a $12 \%$ SDS-polyacrylamide Criterion gel (Bio-Rad) at $180 \mathrm{~V}$. After electrophoretic separation, proteins were transferred to $0 \cdot 45-\mu \mathrm{m}$ nitrocellulose membranes in a trans-blot turbo transfer system (30 min at $25 \mathrm{~V}$; Bio-Rad). Subsequently, the membranes were stained with Ponceau $\mathrm{S}$ to check for protein bands. Following destaining, blots were blocked for $1 \mathrm{~h}$ in Tris-buffered saline containing $0 \cdot 1 \%$ Tween 20 (TBST) and 5\% non-fat dry milk powder. Thereafter, blots were incubated overnight at $4^{\circ} \mathrm{C}$ with primary antibodies against $\beta$-actin (1:1000 dilution; Santa Cruz), BiP (1:300 dilution; R\&D Systems), calnexin (1:1000 dilution; Cell signaling), HSP27 (1:1000 dilution; Cell signaling), HSP70 (1:1000 dilution; R\&D Systems), SOD1 (1:800 dilution; R\&D Systems) and SOD2 (1:1000 dilution; R\&D Systems) in TBST containing $5 \%$ non-fat dry milk powder. After incubation with primary antibodies, membranes were washed three times for $10 \mathrm{~min}$ with TBST and incubated for $1.5 \mathrm{~h}$ with a 1:10000 dilution of horseradish peroxidase-conjugated secondary antibody (DAKO) in TBST containing 5\% non-fat dry milk powder. After washing, bands were visualised using a chemiluminescent substrate (SuperSignal CL; Thermo Fischer Scientific) and a charge-coupled device (CCD) camera (XRS system; Bio-Rad). Data were quantified using Image Lab ${ }^{\mathrm{TM}} 4.0$ Software (Bio-Rad).

A pooled sample was used to correct for differences between blots. Blots were normalised using all protein bands seen with Ponceau $\mathrm{S}$ as a measure of total protein in the sample instead of a housekeeping protein. Generally used housekeeping proteins such as $\beta$-actin are influenced by dieting as previously shown in the $2 \mathrm{D}$-gel electrophoresis analysis by Bouwman et $a l^{(39)}$, whereas Ponceau S has recently been indicated to be a suitable alternative for housekeeping proteins ${ }^{(40)}$.

\section{HSP60 plasma concentrations}

Plasma samples were stored at $-80^{\circ} \mathrm{C}$ after collection. HSP60 concentrations were determined by ELISA (Cusabio Biotech) following the manufacturer's instructions. Absorbance was read by a spectrophotometer at $450 \mathrm{~nm}$.

\section{Statistical analyses}

Independent $T$ test was carried out for baseline comparisons between WM and WR. ANOVA repeated measures were carried out to determine possible differences over time within a group for the human intervention study. For the in vitro measurements, a dependent $T$ test was carried out to determine differences between control cells and glucose-restricted cells. The dependent $T$ test was used because control cells and glucosestarved cells originate from the same cultured pre-adipocytes. For the human study, fold changes during weight loss and during the whole study were evaluated by ratio of the values in $\mathrm{t} 2$ : $\mathrm{t} 0$ and $\mathrm{t} 12: \mathrm{t} 0$, respectively. Fold change comparisons between WM and WR were performed by using independent $T$ test.

Pearson's $R$ and Spearman's $\rho$ correlation coefficients were calculated for relationships between parameters during the dieting period. Only correlations found significant with both tests were reported, this was done to make the analysis more stringent and reliable. The Spearman rank correlation might be the preferred method as we do not a priori know whether the protein changes are in a linear relationship. On the other hand, when proteins are closely functionally interacting, a linear relationship might be expected. Therefore, we decided to select only values that were significant $(P<0 \cdot 01)$ with both methods. Statistical analyses were carried out using SPSS 20.0 for Windows (SPSS Inc.). For all statistical tests, $P<0.05$ was considered to be statistically significant, except for correlations $(P<0 \cdot 01)$. Variation in the number of participants between analyses is due to the exclusion of subjects with missing data. All variables were checked for normal distribution, and variables with a skewed distribution were ln-transformed to satisfy conditions of normality. Extreme outliers (values higher than $3 \times$ interquartile range calculated with SPSS) influencing the data were removed during statistical analyses. Data are presented as mean values with their standard errors, unless otherwise indicated.

\section{Results}

\section{Subject characteristics}

No significant difference was observed between the WM and the WR group for baseline weight and BMI. Body weight was significantly reduced after diet in both the groups, and during follow-up weight gain was significant in the WR group $(P<0 \cdot 001)$, but not in the WM group (Table 1$)$. The WR group decreased weight by $14.3 \%$ and regained $8.2 \%$ of the weight 
Table 1. Subject characteristic of the two groups (weight regainers (WR) weight maintainers (WM)) at time points t0, t2 and $t 12^{*}$ (Mean values with their standard errors)

\begin{tabular}{|c|c|c|c|c|c|c|}
\hline & \multicolumn{2}{|c|}{ to } & \multicolumn{2}{|c|}{ t2 } & \multicolumn{2}{|c|}{$\mathrm{t} 12$} \\
\hline & Mean & SEM & Mean & SEM & Mean & SEM \\
\hline \multicolumn{7}{|l|}{ WM } \\
\hline Sex (male/female) & \multicolumn{2}{|c|}{$5 / 4$} & \multicolumn{2}{|c|}{$5 / 4$} & \multicolumn{2}{|c|}{$5 / 4$} \\
\hline Weight (kg)† & 95.4 & $5 \cdot 7$ & $81 \cdot 7$ & $4 \cdot 6$ & $82 \cdot 8$ & $5 \cdot 5$ \\
\hline BMI $\left(\mathrm{kg} / \mathrm{m}^{2}\right) \dagger$ & $32 \cdot 0$ & 0.7 & 27.5 & 0.7 & $27 \cdot 7$ & 0.8 \\
\hline \multicolumn{7}{|l|}{ WR } \\
\hline Sex (male/female) & \multicolumn{2}{|c|}{$4 / 5$} & \multicolumn{2}{|c|}{$4 / 5$} & \multicolumn{2}{|c|}{$4 / 5$} \\
\hline Weight (kg)†‡ & 95.4 & $5 \cdot 7$ & $81 \cdot 8$ & $5 \cdot 0$ & $89 \cdot 1$ & $5 \cdot 3$ \\
\hline BMI $\left(\mathrm{kg} / \mathrm{m}^{2}\right) \dagger \ddagger$ & 31.5 & $1 \cdot 1$ & $27 \cdot 1$ & $1 \cdot 1$ & $29 \cdot 4$ & $1 \cdot 1$ \\
\hline
\end{tabular}

* Repeated-measures ANOVA between time points.

$\dagger P<0.001$ (t0-t2).

$\ddagger P<0.001$ (t2-t12).
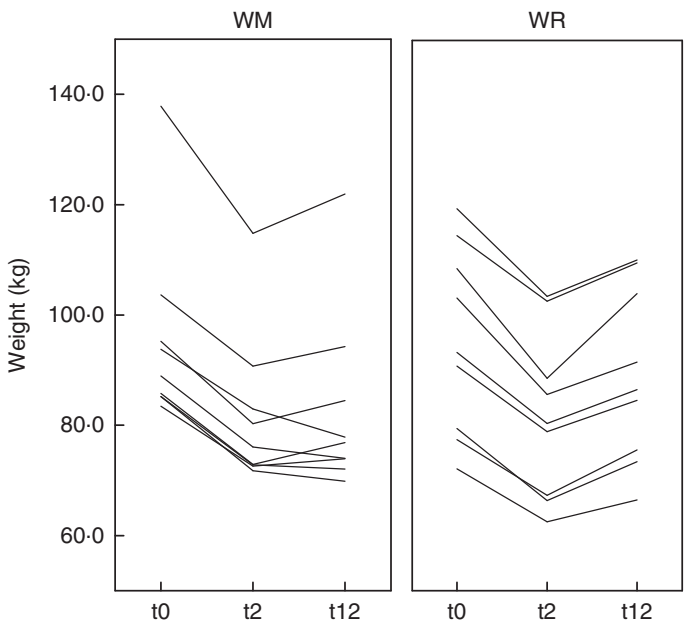

Fig. 1. Body weight progression during the course of the study for weight maintainers (WM; $n$ 9) and weight regainers (WR; $n$ 9). Each line represents the body weight $(\mathrm{kg})$ of an individual measured before 8 weeks of a very lowenergy diet (t0), after the very low-energy diet (t2), and after 10 months of follow-up (t12).

at $\mathrm{t} 2$. The WM group decreased weight by $14.4 \%$ and only regained $0.9 \%$. Fig. 1 shows individual weight changes of the WM and WR groups.

\section{Stress-related proteins in adipose tissue after energy restriction}

After weight loss, $\beta$-actin, BiP, calnexin, HSP27, HPS60 and HSP70 levels decreased in the WM group, whereas an increase was observed in the WR group as shown in Table 2. Fold changes between two time points were calculated and compared between the WR and the WM group (Fig. 2). During the weight loss period ( $\mathrm{t} 0-\mathrm{t} 2)$, the WR group differed from the WM group with respect to $\beta$-actin (trend), calnexin (trend), HSP27 (trend), HSP60 and HSP70 (Fig. 2(a)). Levels of stress proteins changed only during weight loss, as during the follow-up period (t2-t12) no change for any protein was observed (data not shown). After the complete intervention
Table 2. Protein abundance levels measured by Western blot at three time points*

(Mean values with their standard errors)

\begin{tabular}{|c|c|c|c|c|c|c|}
\hline & \multicolumn{2}{|c|}{ to } & \multicolumn{2}{|c|}{$\mathrm{t} 2$} & \multicolumn{2}{|c|}{$\mathrm{t} 12$} \\
\hline & Mean & SEM & Mean & SEM & Mean & SEM \\
\hline \multicolumn{7}{|l|}{$\beta$-Actin } \\
\hline WM & 3.93 & 0.58 & 3.51 & 0.48 & 3.72 & 0.56 \\
\hline WR & 4.03 & 0.51 & 4.93 & 0.45 & $4 \cdot 27$ & 0.46 \\
\hline \multicolumn{7}{|l|}{$\mathrm{BiP}$} \\
\hline WM† & 3.82 & 1.09 & 1.27 & 0.60 & 1.92 & 0.47 \\
\hline WR $\ddagger \S$ & 1.54 & 0.54 & $2 \cdot 12$ & 0.69 & 3.59 & 0.53 \\
\hline \multicolumn{7}{|l|}{ Calnexin } \\
\hline WM & $2 \cdot 88$ & $1 \cdot 26$ & 0.76 & 0.28 & $1 \cdot 20$ & 0.51 \\
\hline WR & $1 \cdot 36$ & 0.58 & 3.62 & $1 \cdot 38$ & 1.73 & 0.96 \\
\hline \multicolumn{7}{|l|}{ HSP27 } \\
\hline WM† & 3.46 & 1.25 & $2 \cdot 60$ & 1.88 & 1.58 & 0.81 \\
\hline WR & 2.56 & 1.50 & $5 \cdot 80$ & 2.44 & 2.98 & $1 \cdot 22$ \\
\hline \multicolumn{7}{|l|}{ HSP60 } \\
\hline WMII & $4 \cdot 40$ & 1.34 & 1.46 & 0.60 & $2 \cdot 87$ & 0.78 \\
\hline WR & $2 \cdot 80$ & 0.54 & 3.66 & 0.67 & 3.92 & 0.79 \\
\hline \multicolumn{7}{|l|}{ HSP70 } \\
\hline WM & 2.77 & 0.68 & $2 \cdot 30$ & 1.00 & 2.48 & 0.38 \\
\hline WR\|§ & $2 \cdot 17$ & 0.55 & 3.85 & 0.90 & 4.50 & 0.72 \\
\hline \multicolumn{7}{|l|}{ SOD1 } \\
\hline WM & 1.04 & 0.29 & 1.57 & 0.49 & $1 \cdot 17$ & 0.29 \\
\hline WR & 0.96 & 0.43 & 1.40 & 0.41 & $1 \cdot 12$ & 0.40 \\
\hline \multicolumn{7}{|l|}{ SOD2 } \\
\hline WM & $1 \cdot 17$ & 0.42 & 1.64 & 0.94 & $1 \cdot 22$ & 0.51 \\
\hline WR & $1 \cdot 71$ & 0.60 & $2 \cdot 51$ & 0.63 & 1.66 & 0.61 \\
\hline
\end{tabular}

WM, weight maintainers; WR, weight regainers; BiP, binding Ig protein; HSP, heat shock protein; SOD, superoxide dismutase.

* Repeated-measures ANOVA between time points.

$\dagger P>0.05-P<0.1$ (t0-t2).

$\ddagger P<0.05(\mathrm{t} 2-\mathrm{t} 12)$.

$\S P<0.05$ (t0-t12).

$\| P<0.05$ (t0-t2).

(t0-t12), the WR group still differed from the WM group with respect to HSP27 (trend) and HSP70 (Fig. 2(b)). BiP, SOD1 and SOD2 did not significantly change during weight loss. After dieting, no significant difference in plasma HSP60 levels was observed between the WR and the WM group. In addition, plasma HSP60 levels did not reflect HSP60 concentrations in adipose tissue (data not shown).

During the weight loss phase, changes in stress proteins were correlated in both groups to be able to gain more insight into the mechanistic regulation of weight loss-induced cellular stress. In online Supplementary Fig. S1, the correlation plots can be observed. On the basis of these significant correlations, we have drawn interaction maps for the WM and WR groups (Fig. 3). In both groups, the similar regulation of HSP60 with HSP70 is obvious; however, although in the WM group a link between $\beta$-actin and HSP27 exists, in the WR group these proteins seem to follow the regulation of HSP60.

\section{Stress-related proteins in adipocytes after low glucose starvation}

The in vivo results were based on adipose tissue biopsies, which in addition to adipocytes also contain stromal vascular cells. To investigate whether there is an adipocyte-specific stress response to energy restriction, we performed an in vitro experiment. Mature SGBS adipocytes received glucose-restricted medium for 
(a)

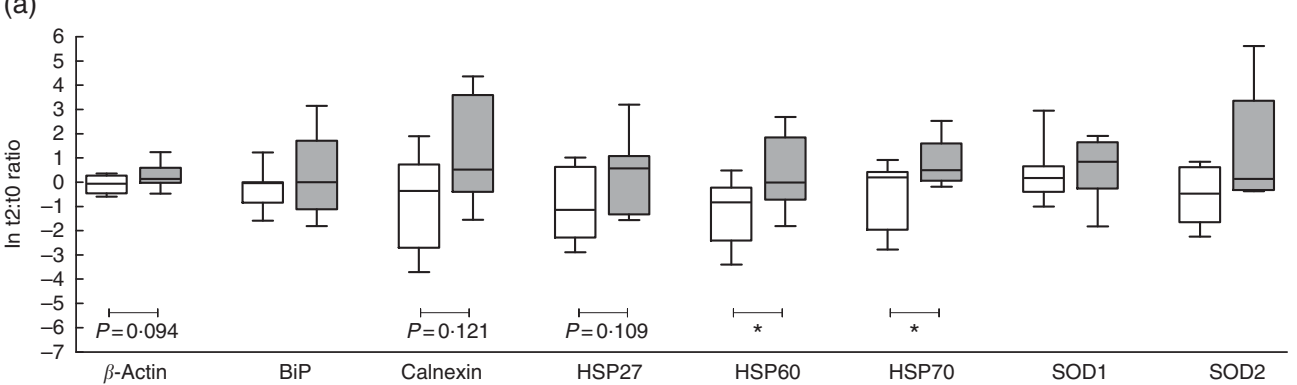

(b)

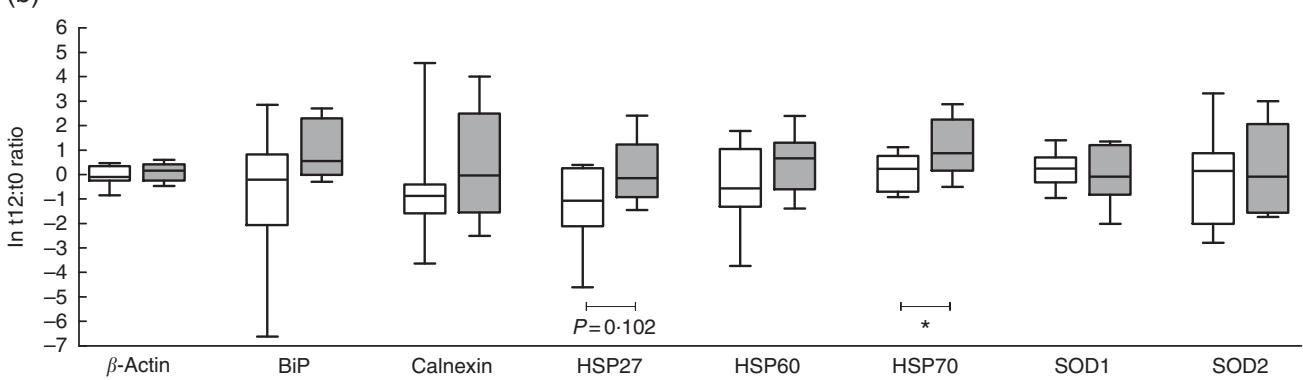

Fig. 2. Fold changes in stress-related proteins during (a) the weight loss-phase (after 8 weeks of weight loss (t2):baseline (t0)) and (b) the whole study (after 10 months of follow-up (t12):t0). Each box plot shows the median and interquartile range without outliers of the fold change in each protein. Weight maintainers $(\square ; n 9)$ and weight regainers $(\square ; n 9)$. The difference between the two groups was analysed by independent $t$ test on In-transformed values. $P$ values below 0.05 are considered significantly different. BiP, binding immunoglobulin protein; HSP, heat shock protein; SOD, superoxide dismutase.
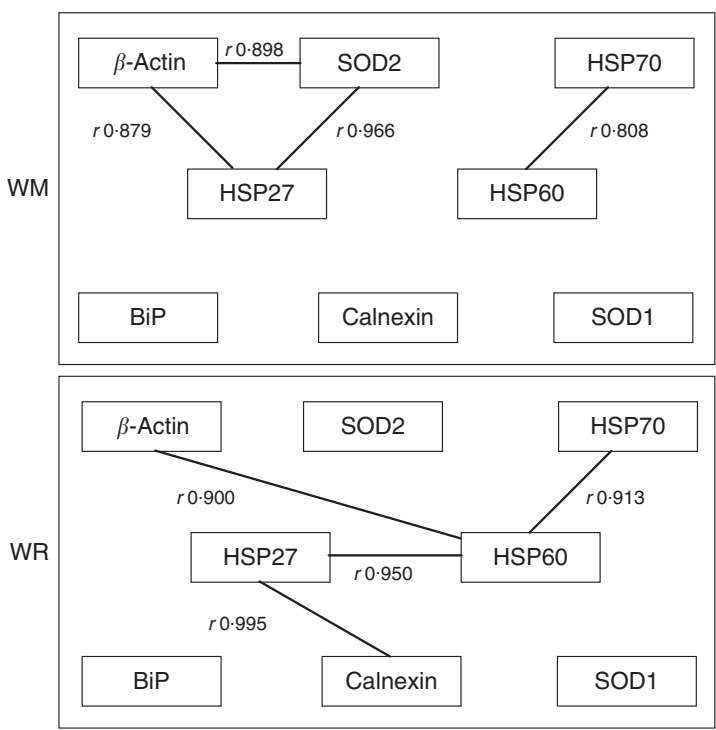

Fig. 3. Schematic overview of the correlated proteins within the weight maintainers (WM) and weight regainers (WR) groups during the diet phase (t0-t2). Significant correlations $(P<0.01)$ found with both Pearson $R$ and Spearman $\rho$ are represented by the connecting lines with the correlation coefficients $(r)$. SOD, superoxide dismutase; HSP, heat shock protein; BiP, binding immunoglobulin protein.

$4 \mathrm{~d}$ causing around $17 \%$ loss of TAG content from the cells as previously reported by Renes et al. ${ }^{(38)}$. In parallel, mature SGBS adipocytes cultured with control medium did not show loss of TAG. Cells were then harvested and proteins were isolated. The relative amounts of the eight proteins were measured, but SOD1 expression appeared to be too low to measure. Similar to the WR

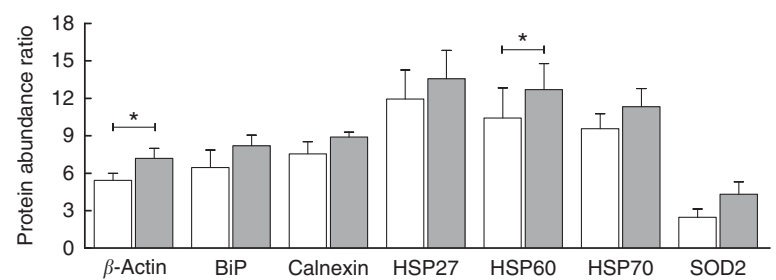

Fig. 4. Stress protein levels of Simpson-Golabi-Behmel syndrome adipocytes after glucose restriction measured with Western blotting. Glucose restriction medium containing $20 \mathrm{nM}$-insulin and $0.55 \mathrm{mM}$-glucose $(\square)$. The control group received medium with $20 \mathrm{nM}$-insulin and $17.5 \mathrm{mM}$-glucose $(\square)$. All groups consist of $n 3$ measured in duplicate. Values are means, with standard errors represented by vertical bars. ${ }^{*} P<0.05$ with dependent $t$ test. BiP, binding immunoglobulin protein; HSP, heat shock protein; SOD, superoxide dismutase.

group, expressions of all measured stress proteins were increased during energetic restriction with statistical significance for $\beta$-actin and HSP60 (Fig. 4).

\section{Discussion}

The results of the present study suggest that adipocyte stress is a biological risk factor for weight regain after weight loss. In the WR group, the levels of $\beta$-actin, calnexin, HSP27, HSP60 and HSP70 were increased after weight loss compared with the WM group. Correlation analysis indicated that changes in $\beta$-actin, HSP70 and HSP27 are linked to changes in HSP60 as a possible key factor contributing to weight regain. Increased levels of $\beta$-actin and HSP60 were also observed after $4 \mathrm{~d}$ of glucose restriction of SGBS adipocytes, indicating that the in vivo observations reside in the mature adipocytes of the adipose tissue. 
Our findings show that during weight loss stress proteins increase in the adipose tissue of individuals who are at risk for weight regain. One of those is $\beta$-actin, a component of actin filaments ${ }^{(27)}$. During weight loss, adipocytes change shape due to shrinking, which requires re-allocation of cellular components. When parts of the cell need to be moved, 10-30 actin filaments assemble into so-called stress-fibres, which can perform mechanical traction. Accordingly, in our in vitro experiment with cultured SGBS adipocytes, we observed a significant up-regulation of $\beta$-actin after glucose restriction in parallel to the loss of TAG and shrinking of the cells. In the adipose tissue of the WR subjects after weight loss, we observed an up-regulation of $\beta$-actin, indicating that more stress-fibres are formed and more mechanical stress exists in the adipocytes of the WR group than in those of the WM group. Unfortunately, we were unable to quantify stress fibres directly. Nevertheless, our $\beta$-actin results are in line with those of Mutch et al. ${ }^{(41)}$ who detected an up-regulation of $\beta$-actin gene expression in the WR group and a down-regulation in the WM group.

HSP27 showed a trend for change in adipose tissue after weight loss and there was no change after glucose restriction in the in vitro cultured adipocytes. On the other hand, in the WM group, we found a strong correlation between HSP27 and $\beta$-actin, suggesting a functional link between these proteins. It has been shown that HSP27 binds to actin filaments (F-actin) and that under cell stress HSP27 becomes phosphorylated, which enhances binding affinity for F-actin ${ }^{(42)}$. In this regard, HSP27 appears to be involved in the regulation of actin filament dynamics. In renal cells, HSP27 provides protection against the consequences of ATP depletion and this function is dependent on $\mathrm{HSP}^{(43)}$, which is known to form complexes with HSP $60^{(44)}$. In the present study, our correlation map of the WR group showed a link between changes over the diet period for $\beta$-actin, HSP27 and HSP70 via HSP60 (Fig. 3). Altogether, these data in combination with our in vitro response to energy depletion strongly suggest that weight regain relates to cell stress and involves the regulation of actin filament dynamics.

Calnexin increased in the adipose tissue in the WR group after weight loss, whereas in the other group the level seemed to drop. Calnexin retains newly synthesised $\mathrm{N}$-glycosylated proteins inside the ER to ensure proper folding with the help of folding factor ERp $57^{(29,30)}$. Wrongly folded proteins may enter into a cycle of unfolding and refolding or may be broken down by the ER-associated degradation pathway ${ }^{(45)}$, whereas correctly folded glycoproteins are transported out of the cell. Interestingly, $\mathrm{N}$-glycoproteins are important for the formation of the extracellular matrix (ECM) of adipocytes ${ }^{(46)}$. Our results showed relatively high levels of calnexin after dieting in the WR group, which seems to be in line with the up-regulation of genes with a focal adhesion function in the WR group of the study of Mutch et $a l^{(41)}$ and their down-regulation in the WM group.

Besides mechanical stress, other forms of cellular stress might be involved in the risk for weight regain after weight loss. HSP70 is a marker for ER stress, although it may also have a protective function against ER stress-induced apoptosis ${ }^{(47)}$, possibly by inhibiting key stress kinases ${ }^{(48)}$. Our results show increased concentrations of HSP70 after dieting in the WR group. This implies that ER stress is present in the adipose tissue of those subjects and as such might be related to the risk of weight regain after weight loss.

In this study, we found that the WR group had elevated levels of HSP60 in the adipose tissue after dieting compared with WM subjects. HSP 60 is present in the circulation of people with type 2 diabetes $^{(49)}$ and increased levels are observed in the adipose tissue of obese subjects compared with lean subjects ${ }^{(2)}$. In starved 3T3-L1 adipocytes, an up-regulation of HSP60 is shown compared with non-starved cells ${ }^{(50)}$, which complies with our present in vitro observations in human SGBS adipocytes. HSP60 stimulates the release of pro-inflammatory adipokines from the adipose tissue, promoting inflammation and, as such, may support the development of insulin resistance. This suggests that WR subjects are at higher risk for obesity-related complications. Interestingly, as HSP60 is a chaperone for mitochondrial proteins, an increase in HSP60 after weight loss indicates a dysregulation of the mitochondrial metabolic processes in WR subjects. However, a possible role for such impairment in the risk of weight regain requires further investigation.

A limitation of the present study is the relatively small number of participants. In this group, the age varied between 20 and 55 years and the BMI between 27 and $39 \mathrm{~kg} / \mathrm{m}^{2}$. Thus, it might be that we included pre- and post-menopausal woman as well as overweight and obese individuals. Nevertheless, this study produced new insights that can form the basis for further studies in larger cohorts. For the moment, it is unclear why some people show increased adipose cellular stress during weight loss while others do not. One explanation might be genetic predisposition. Alternatively, adipocyte size at baseline might play a role. A general model for accumulation of cellular stress during weight loss states that when adipocytes lose fat and shrink, the surrounding ECM is unable to follow the size reduction $^{(51-53)}$. Consequently, mechanical-type cellular stress rises, which can be neutralised most easily by renewed lipid uptake and storage. Indeed, measuring the adipocyte molecular metabolism using proteomics technologies indicates that after returning to energy balance adipocytes rapidly prepare for re-storing $\mathrm{TAG}^{(39,54)}$. Moreover, during weight loss, the plasma leptin level decreases dramatically, out of proportion with the loss of fat mass, which implies that, after weight loss, an extra impulse is given to energy intake to warrant the re-storing of fat and release of cellular stress ${ }^{(55)}$.

In conclusion, analyses of subcutaneous adipose tissue show increased cellular stress after an 8-week diet in a group of subjects who regained most of their weight during follow-up. In vitro cultured mature adipocytes subjected to energy restriction showed similar protein changes. These findings support the idea that adipocyte stress plays a role as a biological risk factor for weight regain after weight loss and suggest involvement of mechanical stress with dynamics of stress fibres.

\section{Acknowledgements}

The authors acknowledge the participants for cooperation in this study. The authors thank Ping Wang for helpful discussions and advice. 
This work was supported by the Netherlands Organisation for Scientific Research TOP (grant number 200500001). The Netherlands Organisation for Scientific Research had no role in the design, analyses or writing of this article.

E. C. M. M. and N. J. T. R. designed the study. N. J. T. R., S. G. C., J. R. and F. G. B. collected the data. N. J. T. R. analysed the data and wrote the manuscript. E. C. M. M. and K. R. W. contributed to the interpretation of the data and reviewed the manuscript. The study was executed under the supervision of E. C. M. M. All the authors read and approved the final version of the manuscript.

The authors declare that there are no conflicts of interest.

\section{Supplementary material}

For supplementary material/s referred to in this article, please visit http://dx.doi.org/doi:10.1017/S0007114515005139

\section{References}

1. Bessesen DH (2008) Update on obesity. J Clin Endocrinol Metab 93, 2027-2034.

2. Wing RR \& Hill JO (2001) Successful weight loss maintenance. Ann Rev Nutr 21, 323-341.

3. Wu T, Gao X, Chen M, et al. (2009) Long-term effectiveness of diet-plus-exercise interventions vs. diet-only interventions for weight loss: a meta-analysis. Obes Rev 10, 313-323.

4. Barte JC, ter Bogt NC, Bogers RP, et al. (2010) Maintenance of weight loss after lifestyle interventions for overweight and obesity, a systematic review. Obes Rev 11, 899-906.

5. Blomain ES, Dirhan DA, Valentino MA, et al. (2013) Mechanisms of weight regain following weight loss. ISRN Obes 2013, 210524.

6. Delahanty LM, Pan Q, Jablonski KA, et al. (2014) Effects of weight loss, weight cycling, and weight loss maintenance on diabetes incidence and change in cardiometabolic traits in the Diabetes Prevention Program. Diabetes Care 37, 2738-2745.

7. Elfhag K \& Rossner S (2005) Who succeeds in maintaining weight loss? A conceptual review of factors associated with weight loss maintenance and weight regain. Obes Rev 6, 67-85.

8. Yost TJ, Jensen DR \& Eckel RH (1995) Weight regain following sustained weight reduction is predicted by relative insulin sensitivity. Obes Res 3, 583-587.

9. Wing RR (1997) Insulin sensitivity as a predictor of weight regain. Obes Res 5, 24-29.

10. Wong MH, Holst C, Astrup A, et al. (2012) Caloric restriction induces changes in insulin and body weight measurements that are inversely associated with subsequent weight regain. PLOS ONE 7, e42858.

11. Wang P, Menheere PP, Astrup A, et al. (2013) Metabolic syndrome, circulating RBP4, testosterone, and SHBG predict weight regain at 6 months after weight loss in men. Obesity (Silver Spring) 21, 1997-2006.

12. Aller EE, Larsen TM, Claus H, et al. (2014) Weight loss maintenance in overweight subjects on ad libitum diets with high or low protein content and glycemic index: the DIOGENES trial 12-month results. Int J Obes 38, 1511-1517.

13. Crujeiras AB, Pardo M, Arturo RR, et al. (2014) Longitudinal variation of circulating irisin after an energy restrictioninduced weight loss and following weight regain in obese men and women. Am J Hum Biol 26, 198-207.

14. Wang P, Holst C, Wodzig WK, et al. (2012) Circulating ACE is a predictor of weight loss maintenance not only in overweight and obese women, but also in men. Int J Obes (Lond) 36, $1545-1551$.
15. Crujeiras AB, Goyenechea E, Abete I, et al. (2010) Weight regain after a diet-induced loss is predicted by higher baseline leptin and lower ghrelin plasma levels. J Clin Endocrinol Metab 95, 5037-5044.

16. Crujeiras AB, Campion J, Diaz-Lagares A, et al. (2013) Association of weight regain with specific methylation levels in the NPY and POMC promoters in leukocytes of obese men: a translational study. Regul Pept 186, 1-6.

17. Vogels N, Diepvens K \& Westerterp-Plantenga MS (2005) Predictors of long-term weight maintenance. Obes Res $\mathbf{1 3}$, $2162-2168$

18. Vogels N \& Westerterp-Plantenga MS (2007) Successful long-term weight maintenance: a 2-year follow-up. Obesity (Silver Spring) 15, 1258-1266.

19. Mauriège $\mathrm{P}$, Imbeault $\mathrm{P}$, Doucet $\mathrm{E}$, et al. (2013) Weight loss and regain in obese individuals: a link with adipose tissue metabolism indices? J Physiol Biochem 69, 497-505.

20. Koppo K, Siklova-Vitkova M, Klimcakova E, et al. (2012) Catecholamine and insulin control of lipolysis in subcutaneous adipose tissue during long-term diet-induced weight loss in obese women. Am J Physiol Endocrinol Metab 302, E226-E232.

21. Verhoef SP, Camps SG, Bouwman FG, et al. (2013) Physiological response of adipocytes to weight loss and maintenance. PLOS ONE 8, e 58011.

22. Boden G, Duan X, Homko C, et al. (2008) Increase in endoplasmic reticulum stress-related proteins and genes in adipose tissue of obese, insulin-resistant individuals. Diabetes 57, 2438-2444

23. Sharma NK, Das SK, Mondal AK, et al. (2008) Endoplasmic reticulum stress markers are associated with obesity in nondiabetic subjects. J Clin Endocrinol Metab 93, 4532-4541.

24. Gregor MF, Yang L, Fabbrini E, et al. (2009) Endoplasmic reticulum stress is reduced in tissues of obese subjects after weight loss. Diabetes 58, 693-700.

25. Krautbauer S, Eisinger K, Hader Y, et al. (2014) Manganese superoxide dismutase knock-down in 3T3-L1 preadipocytes impairs subsequent adipogenesis. Mol Cell Biochem 393 , 69-76.

26. Liu GS, Chan EC, Higuchi M, et al. (2012) Redox mechanisms in regulation of adipocyte differentiation: beyond a general stress response. Cells 1, 976-993.

27. Shawlot W, Deng JM, Fohn LE, et al. (1998) Restricted beta-galactosidase expression of a hygromycin-lacZ gene targeted to the beta-actin locus and embryonic lethality of beta-actin mutant mice. Transgenic Res 7, 95-103.

28. Kleizen B \& Braakman I (2004) Protein folding and quality control in the endoplasmic reticulum. Curr Opin Cell Biol 16, 343-349.

29. Guerin R, Arseneault G, Dumont S, et al. (2008) Calnexin is involved in apoptosis induced by endoplasmic reticulum stress in the fission yeast. Mol Biol Cell 19, 4404-4420.

30. Bousette N, Abbasi C, Chis R, et al. (2014) Calnexin silencing in mouse neonatal cardiomyocytes induces Ca2+ cycling defects, ER stress, and apoptosis. J Cell Physiol 229, 374-383.

31. Garrido C (2002) Size matters: of the small HSP27 and its large oligomers. Cell Death Differ 9, 483-485.

32. Horman S, Galand P, Mosselmans R, et al. (1997) Changes in the phosphorylation status of the $27 \mathrm{kDa}$ heat shock protein (HSP27) associated with the modulation of growth and/or differentiation in MCF-7 cells. Cell Prolif 30, 21-35.

33. Marker T, Sell H, Zillessen P, et al. (2012) Heat shock protein 60 as a mediator of adipose tissue inflammation and insulin resistance. Diabetes 61, 615-625.

34. Mayer RJ, Ciechanover AJ \& Rechsteiner M (2005) Protein Degradation. Weinheim: Wiley-VCH. 
35. Toichi K, Yamanaka K \& Furukawa Y (2013) Disulfide scrambling describes the oligomer formation of superoxide dismutase (SOD1) proteins in the familial form of amyotrophic lateral sclerosis. J Biol Chem 288, 4970-4980.

36. Wang P, Bouwman FG \& Mariman EC (2009) Generally detected proteins in comparative proteomics - a matter of cellular stress response? Proteomics 9, 2955-2966.

37. Wabitsch M, Brenner RE, Melzner I, et al. (2001) Characterization of a human preadipocyte cell strain with high capacity for adipose differentiation. Int J Obes Relat Metab Disord 25 , $8-15$.

38. Renes J, Rosenow A, Roumans N, et al. (2014) Calorie restriction-induced changes in the secretome of human adipocytes, comparison with resveratrol-induced secretome effects. Biochim Biophys Acta 1844, 1511-1522.

39. Bouwman FG, Claessens M, van Baak MA, et al. (2009) The physiologic effects of caloric restriction are reflected in the in vivo adipocyte-enriched proteome of overweight/obese subjects. J Proteome Res $\mathbf{8}, 5532-5540$.

40. Gilda JE \& Gomes AV (2013) Stain-free total protein staining is a superior loading control to beta-actin for Western blots. Anal Biochem 440, 186-188.

41. Mutch DM, Pers TH, Temanni MR, et al. (2011) A distinct adipose tissue gene expression response to caloric restriction predicts 6-mo weight maintenance in obese subjects. $\mathrm{Am} \mathrm{J}$ Clin Nutr 94, 1399-1409.

42. Clarke JP \& Mearow KM (2013) Cell stress promotes the association of phosphorylated HspB1 with F-actin. PLOS ONE 8, e68978.

43. Sreedharan R, Riordan M, Thullin G, et al. (2011) The maximal cytoprotective function of the heat shock protein 27 is dependent on heat shock protein 70. Biochim Biophys Acta 1813, 129-135.

44. Sarto C, Binz PA \& Mocarelli P (2000) Heat shock proteins in human cancer. Electrophoresis 21, 1218-1226.
45. Helenius A \& Aebi M (2001) Intracellular functions of N-linked glycans. Science 291, 2364-2369.

46. Jones FS \& Jones PL (2000) The tenascin family of ECM glycoproteins: structure, function, and regulation during embryonic development and tissue remodeling. Dev Dyn 218, 235-259.

47. Mosser DD, Caron AW, Bourget L, et al. (2000) The chaperone function of hsp70 is required for protection against stress-induced apoptosis. Mol Cell Biol 20, 7146-7159.

48. Simar D, Jacques A \& Caillaud C (2012) Heat shock proteins induction reduces stress kinases activation, potentially improving insulin signalling in monocytes from obese subjects. Cell Stress Chaperones 17, 615-621.

49. Dasu MR, Devaraj S, Park S, et al. (2010) Increased toll-like receptor (TLR) activation and TLR ligands in recently diagnosed type 2 diabetic subjects. Diabetes Care 33, 861-868.

50. Renes J, Bouwman F, Noben JP, et al. (2005) Protein profiling of 3T3-L1 adipocyte differentiation and (tumor necrosis factor alpha-mediated) starvation. Cell Mol Life Sci 62, 492-503.

51. Kolehmainen M, Salopuro T, Schwab US, et al. (2008) Weight reduction modulates expression of genes involved in extracellular matrix and cell death: the GENOBIN study. Int $J$ Obes (Lond) 32, 292-303.

52. Mariman EC (2012) Human biology of weight maintenance after weight loss. J Nutrigenet Nutrigenomics 5, 13-25.

53. Mariman EC (2011) An adipobiological model for weight regain after weight loss. Adipobiology 3, 9-15.

54. Bouwman FG, Wang $P$, van Baak M, et al. (2014) Increased beta-oxidation with improved glucose uptake capacity in adipose tissue from obese after weight loss and maintenance. Obesity (Silver Spring) 22, 819-827.

55. Maffei M, Halaas J, Ravussin E, et al. (1995) Leptin levels in human and rodent: measurement of plasma leptin and ob RNA in obese and weight-reduced subjects. Nat Med $\mathbf{1}$, $1155-1161$. 